\title{
Comparison of trauma systems in Asian countries: a cross-sectional study
}

Young Hee Jung ${ }^{1}$, Dae Han $\mathrm{Wi}^{2}$, Sang Do Shin ${ }^{3}$, Hideharu Tanaka ${ }^{4}$, Goh E. Shaunn, Wen-Chu Chiang ${ }^{6}$, Jen-Tang Sun ${ }^{7}$, Li-Min Hsu', Kentaro Kajino ${ }^{9}$, Sabariah Faizah Jamaluddin ${ }^{10}$, Akio Kimura ${ }^{11}$, James F. Holmes ${ }^{12}$, Kyoung Jun Song ${ }^{3}$, Young Sun Ro ${ }^{1}$, Ki Jeong Hong ${ }^{3}$, Sung Woo Moon ${ }^{13}$, Ju Ok Park ${ }^{14}$, Min Jung Kim ${ }^{1}$

\author{
'Laboratory of Emergency Medical Services, Seoul National University Hospital Biomedical Research \\ Institute, Seoul, Korea \\ ${ }^{2}$ Department of Emergency Medicine, Wonkwang University School of Medicine, Iksan, Korea \\ ${ }^{3}$ Department of Emergency Medicine, Seoul National University Hospital, Seoul National University College \\ of Medicine, Seoul, Korea \\ ${ }^{4}$ Department of Emergency Medical System, Graduate School of Kokushikan University, Tokyo, Japan \\ ${ }^{5}$ Acute and Emergency Care Center, Khoo Teck Paut Hospital, Singapore \\ ${ }^{6}$ Department of Emergency Medicine, National Taiwan University Hospital, National Taiwan University \\ College of Medicine, Taipei, Taiwan \\ ${ }^{7}$ Department of Emergency Medicine, Far Eastern Memorial Hospital, New Taipei, Taiwan \\ ${ }^{8}$ Department of Traumatology and Critical Care, National Taiwan University Hospital, Taipei, Taiwan \\ ${ }^{9}$ Traumatology and Critical Care Medical Center, National Hospital Organization Osaka National Hospital, \\ Osaka, Japan \\ ${ }^{10}$ Emergency and Trauma Department, Sungai Buloh Hospital, Selangor, Malaysia \\ ${ }^{11}$ Department of Emergency Medicine and Critical Care, Center Hospital of the National Center for Global \\ Health and Medicine, Tokyo, Japan \\ ${ }^{12}$ Department of Emergency Medicine, UC Davis Medical Center (JFH), Sacramento, CA, USA \\ ${ }^{13}$ Department of Emergency Medicine, Korea University Ansan Hospital, Ansan, Korea \\ ${ }^{14}$ Department of Emergency Medicine, Hallym University Dongtan Sacred Hospital, Hallym University \\ College of Medicine, Dongtan, Korea
}

Objective This study aimed to compare the demographic characteristics and trauma service structures and processes of hospitals in 15 countries across the Asia Pacific, and to provide baseline data for the integrated trauma database: the Pan-Asian Trauma Outcomes Study (PATOS).

Methods Medical directors and emergency physicians at PATOS-participating hospitals in countries across the Asia Pacific were surveyed through a standardized questionnaire. General information, trauma care system data, and trauma emergency department (ED) outcomes at each hospital were collected by email and analyzed using descriptive statistics.

Results Survey data from 35 hospitals across 15 countries were collected from archived data between June 2014 and July 2015. Designated trauma centers were identified as the highest hospital level for trauma patients in $70 \%$ of surveyed countries. Half of the hospitals surveyed had special teams for trauma care, and almost all prepared activation protocol documents for these teams. Most hospitals offered specialized trauma education programs, and 72.7\% of hospitals had a hospital-based trauma registry. The total number of trauma patients visiting the ED across 25 of the hospitals was 300,376. The overall survival-to-discharge rate was $97.2 \%$; however, it varied greatly between $85.1 \%$ and $99.7 \%$. The difference between survival-to-discharge rates of moderate and severe injury groups was highest in Taiwan (41.8\%) and lowest in Thailand (18.6\%).

Conclusion Trauma care systems and ED outcomes vary widely among surveyed hospitals and countries. This information is useful to build further detailed, systematic platforms for trauma surveillance and evidence-based trauma care policies.

Keywords Trauma; Asian continental ancestry group; Epidemiology
Received: 18 December 2018

Revised: 1 March 2018

Accepted: 11 March 2018

Correspondence to: Dae Han Wi Department of Emergency Medicine, Wonkwang University School of Medicine, 460 Iksandae-ro, Iksan 54538, Korea

E-mail: great@wku.ac.kr ORCID

http://orcid.org/0000-0002-5658-1137

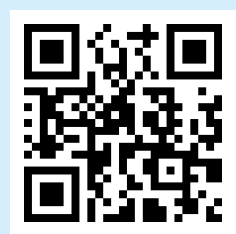

How to cite this article:

Jung YH, Wi DH, Shin SD, Tanaka H, Shaun GE, Chiang WC, Sun JT, Hsu LM, Kajino K, Jamaluddin SF, Kimura A, Holmes JF, Song KJ, Ro YS, Hong KJ, Moon SW, Park JO, Kim MJ. Comparison of trauma systems in Asian countries: a cross-sectional study. Clin Exp Emerg Med 2019;6(4):321-329.

This is an Open Access article distributed under the terms of the Creative Commons Attribution Non-Commercial License (http:// creativecommons.org/licenses/by-nc/4.0/). 


Capsule
Wumat is already known
Most Asian countries recognized their increasing injury burden and have put forth efforts to build qualified trauma care
systems.
What is new in the current study
Half of the hospitals had organized special teams for trauma care and almost all of these prepared activation protocol
documents for their teams. Most hospitals offered specialized trauma education programs, and $72.7 \%$ of hospitals had
a hospital-based trauma registry. The overall survival discharge rate was $97.2 \%$, however, varied greatly between
85.1\% and 99.7\%. A survival difference between moderate and severe injury groups was highest in Taiwan (41.8\%) and
lowest in Thailand (18.6\%).

\section{INTRODUCTION}

The World Health Organization (WHO) reported that injuries cause more than 5 million deaths worldwide each year, and injury mortality is expected to surge by 2030. Injury is one of the leading causes of death during the productive years ( $<45$ years old), leading to significant economic losses. ${ }^{1}$ In addition, injury accounts for $8.3 \%$ of age-standardized disability-adjusted life years (DALYS), with road traffic injuries ranked 8th out of the 20 leading causes of DALYs in 2012. ${ }^{2}$

However, the burden of injury differs by region. One of every ten deaths in Asia is attributed to injury, accounting for more than half of injury-related deaths worldwide. ${ }^{3}$ According to the WHO, injuries were responsible for 87,583 of DALYs per 100,000 people in Southeast Asia in 2012; far more than the 38,903 of DALYs per 100,000 people in high-income countries. Even among Asian countries, there is a large discrepancy. Injury mortality rates vary greatly from 20.6 deaths per 100,000 people in Singapore, to 346.6 per 100,000 people in Myanmar. ${ }^{4}$ Rapid economic development and urbanization are considered contributing factors for the increase in injury-related death and disability in developing countries of this region. ${ }^{3}$

To reduce the burden of injury, a well-functioning trauma care system is essential. The WHO published "Guidelines for essential trauma care" through the Essential Trauma Care Project, and emphasized the importance of establishing trauma care systems to improve trauma treatment, and hence, patient outcomes. Panel studies reported a $50 \%$ average reduction in preventable death rates after the implementation of a trauma system, ${ }_{1}^{5}$ and other studies demonstrated a morbidity and mortality decrease with organized optimal trauma care. ${ }^{6-8}$ The effectiveness of trauma system development has been proven for each component of prehospital, hospital and inter-hospital systems for trauma care. ${ }^{5,79-11}$
Most Asian countries recognize their increasing injury burden and have made efforts to build qualified trauma care systems. ${ }^{12-16}$ However, these efforts have met with varied success because of unequal healthcare resources and resource allocation, along with socioeconomic, cultural, and demographic variance. ${ }^{12-16} \mathrm{~A}$ comprehensive report-based trauma database for Asian countries is required, to identify trauma characteristics in different contexts, monitor discrete trauma systems, and generate evidence-based trauma care policies.

The Pan-Asian Trauma Outcomes Study (PATOS) is an international, multicenter, population-based, cohort study in the Asia Pacific region, proposed in 2013 to create an integrated trauma database. PATOS will collect standardized data on diverse trauma epidemiology, trauma care processes, and outcomes from participating hospital emergency departments across 15 Asian countries for the next 3 years. The objectives of this web-based, cross-sectional, descriptive survey were to examine and compare the demographic characteristics and trauma care service structures, processes and outcomes of trauma care services of PATOS-participating hospitals. Moreover, this study will provide baseline data for PATOS.

\section{METHODS}

\section{Study design and setting}

The study protocol was approved by the institutional review board of Seoul National University College of Medicine (H-1509045-702). This cross-sectional survey was conducted among medical directors and emergency physicians in the emergency medical services (EMSs) and trauma care systems at PATOS-participating hospitals in 15 Asia Pacific countries: Australia, China, Hong Kong, India, Indonesia, Japan, Malaysia, Myanmar, Philippines, South Korea, Singapore, Taiwan, Thailand, Uzbekistan, and Vietnam. 
These 15 countries have varied population characteristics and health indices (Table 1). ${ }^{17-20} \mathrm{~A}$ wide variation in economic status has been observed regarding gross domestic product per capita: five countries have less than $\$ 10,000 /$ capita, four countries have between $\$ 10,000$ and $\$ 30,000 /$ capita, and six countries have more than $\$ 30,000 /$ capita. Health indicators also vary within medical settings. The burden of injury is considerable in India and Myanmar, where more than 100 people die from injuries per 100,000 people, and almost 4,800 years of life lost (YLL) per 100,000 people are attributed to injuries. Developed countries, such as Australia, Singapore, and Japan have low injury mortality rates and YLL. Extraordinarily, the injury mortality in South Korea is 53 deaths per 100,000 people, which is $44 \%$ higher than the average injury mortality rate of high-income countries. In addition, injury-associated YLL is higher in South Korea, with 2,381 YLLs per 100,000 people, compared to an average of 2,142 per 100,000 people in high-income countries. ${ }^{17}$

\section{Study participants}

Survey respondents were trauma surgeons, emergency physicians, general surgeons, and public health, EMS, and hospital officials at PATOS-participating hospitals and EMS systems. Only one survey was permitted per hospital.

\section{Data collection and protocols}

Data were collected from June 2014 to August 2015, through the standardized survey form developed and revised by a team of emergency physicians at the PATOS coordinating center in South Korea. The survey form was sent to every individual on the PATOS mailing list, who submitted their responses to the PATOS coordinating center by e-mail. The hospital survey (Appendix 1) comprised seven questions regarding general hospital information, eight questions on trauma care processes, five questions on trauma education programs, six questions on trauma registries, and twelve questions on trauma outcomes. The PATOS committee validated the survey results and communicated with respondents when errors were found.

\section{Measurements}

General hospital information, such as a country and hospital name, the number of total visits to the ED, and trauma center or hospital level was collected. Urbanization of the community to which the responding hospital belonged was categorized as urban, suburban, rural, or wilderness. We defined "urban" as a city with more than 2,500 inhabitants $/ \mathrm{km}^{2}$ and "rural" with fewer than 2,500 inhabitants $/ \mathrm{km}^{2}$. However, respondents could choose multiple answers from urban, suburban, rural, or wilderness according to their own definition. Trauma center level was categorized as a designated trauma center, a general ED, or a general hospital. Hospital level was classified as tertiary, secondary, or primary care according to their definition.

The trauma care process was identified from the answers to specific questions, such as "Who takes responsibility for the trauma care? Is it a trauma surgeon, emergency physician, general

Table 1. Population characteristics and health indices

\begin{tabular}{|c|c|c|c|c|c|c|c|c|c|c|}
\hline & $\begin{array}{l}\text { Population } \\
\text { (July 2014) }^{17}\end{array}$ & $\begin{array}{l}\text { Population } \\
\text { growth rate } \\
(\%, 2014)^{17}\end{array}$ & $\begin{array}{c}\text { Urban } \\
\text { population } \\
(\%, 2015)^{17}\end{array}$ & $\begin{array}{c}\text { Rate of } \\
\text { urbanization } \\
\text { (\% annual rate } \\
\text { of change, } \\
2010-2015)^{17}\end{array}$ & $\begin{array}{c}\text { GDP per } \\
\text { capita (PPP, } \\
2014, \$)^{17}\end{array}$ & $\begin{array}{c}\text { Life } \\
\text { expectancy } \\
\text { at birth } \\
(y r, 2013)^{17}\end{array}$ & $\begin{array}{c}\text { Infant } \\
\text { mortality } \\
\text { rate }(/ 1,000 \text {, } \\
2014)^{17}\end{array}$ & $\begin{array}{c}\text { Death } \\
\text { rate }(/ 1,000 \text {, } \\
2014)^{17}\end{array}$ & $\begin{array}{c}\text { Age- } \\
\text { standardized } \\
\text { injury mortality } \\
\text { rate }(/ 100,000 \text {, } \\
2012)^{18}\end{array}$ & $\begin{array}{c}\text { Years of life } \\
\text { lost } \\
(/ 100,000 \\
2012)^{18}\end{array}$ \\
\hline Australia & $22,507,617$ & 0.01 & 89.4 & 1.47 & 46,600 & 82.07 & 4.43 & 10.38 & 28 & 1,326 \\
\hline China & $1,355,692,576$ & 0.44 & 55.6 & 3.05 & 12,900 & 75.15 & 14.79 & 7.44 & 50 & 2,208 \\
\hline Hong Kong & $7,112,688$ & 0.41 & 100 & 0.74 & 55,200 & 82.78 & 2.73 & 6.93 & - & - \\
\hline India & $1,236,344,631$ & 1.25 & 32.7 & 2.38 & 5,800 & 67.80 & 43.19 & 7.35 & 116 & 4,785 \\
\hline Indonesia & $253,609,643$ & 0.95 & 53.7 & 2.69 & 10,200 & 72.17 & 25.16 & 6.34 & 49 & 2,116 \\
\hline Japan & $127,103,388$ & -0.13 & 93.5 & 0.56 & 37,800 & 84.46 & 2.13 & 9.38 & 40 & 2,005 \\
\hline Malaysia & $30,073,353$ & 1.47 & 74.7 & 2.66 & 24,500 & 74.52 & 13.69 & 5.00 & 63 & 2,450 \\
\hline Myanmar & $55,746,253$ & 1.03 & 34.1 & 2.49 & 4,800 & 65.94 & 44.91 & 8.01 & 102 & 4,767 \\
\hline Philippines & $107,668,231$ & 1.81 & 44.4 & 1.32 & 7,000 & 72.48 & 17.64 & 4.92 & 54 & 2,698 \\
\hline Korea & $49,039,986$ & 0.16 & 82.5 & 0.66 & 35,400 & 79.80 & 3.93 & 6.63 & 53 & 2,381 \\
\hline Singapore & $5,567,301$ & 1.92 & 100 & 2.02 & 81,300 & 84.38 & 2.53 & 3.42 & 18 & 794 \\
\hline Taiwan & $23,359,928$ & 0.25 & $58.4^{19}$ & - & 43,600 & 79.84 & 4.49 & 6.97 & $43.7^{20}$ & - \\
\hline Thailand & $67,741,401$ & 0.35 & 50.4 & 2.97 & 14,400 & 74.18 & 9.86 & 7.72 & 73 & 3,379 \\
\hline Uzbekistan & $28,929,716$ & 0.93 & 36.4 & 1.45 & 5,600 & 73.29 & 19.84 & 5.29 & 47 & 2,713 \\
\hline Viet Nam & $93,421,835$ & 1.00 & 33.6 & 2.95 & 5,600 & 72.91 & 18.99 & 5.93 & 59 & 2,730 \\
\hline
\end{tabular}

GDP, gross domestic product; PPP, purchasing power parity. 
surgeon, or another department surgeon?" and "Which hospital level is the highest for trauma patients?" In addition, we collected detailed information regarding trauma resources, including trauma teams, trauma surgeons, and trauma centers.

If present, trauma structures, trauma education programs, and registries were described by respondents, who clarified whether their trauma education programs were mandatory, and if the program included operation and critical care practices. Respondents were also asked whether hospital registries were linked to prehospital registries.

ED outcomes included the total number of ED visits, trauma patients' survival-to-discharge rate, and proportion of EMS users among trauma patients. Trauma severity was assessed using the injury severity score (ISS) index: 9-15, 16-24, and >24.

\section{Statistical analysis}

All survey responses were entered into Microsoft Excel (Redmond, WA, USA), and analyzed using descriptive statistics. Although data were collected from individual hospitals, they were compared by country. Trauma care outcomes were only partially reported because of lack of the available information from some hospitals.

\section{RESULTS}

\section{Characteristics of participating hospitals}

PATOS members from thirty-five hospitals received the survey and responded by June 2014 (response rate, 100\%). The total number of ED visits to these hospitals at the time of the survey was 2 million per year, and average visits per hospital was approximately 71,000 . Singapore had the largest number of ED patients per hospital (154,541 visits), and Uzbekistan had the smallest (15,000 visits). Three-quarters of surveyed hospitals were located in urban areas. Twenty-six percent of hospitals $(n=9)$ were designated trauma centers, and others were general hospitals with EDs. The majority of participating hospitals were tertiary care hospitals $(77 \%, n=27)$. Table 2 details the general characteristics of participating hospitals.

\section{Trauma care system: process}

Seventy-two percent of respondents indicated that designated trauma centers were at the highest hospital level for trauma patients, yet respondents in Indonesia, Malaysia, and Uzbekistan all reported that general hospitals with EDs were at the highest hospital level for trauma care. Half of the hospitals in this survey had designated teams for trauma care, and most were prepared with trauma team activation protocols. Australia, Japan, and Indonesia did not have trauma teams, but respondents indicated that docu- mented trauma protocols existed. Trauma care services were provided by emergency physicians and trauma surgeons in $60 \%$ of the surveyed hospitals. Ten countries issued a specific trauma surgeon certification or license. Table 3 details the trauma care process of surveyed hospitals.

\section{Trauma care system: structure}

Most hospitals offered specialized trauma education programs for medical staff $(91 \%, n=30)$ However, only one-third of programs were mandatory. Hospital-based registries for trauma were used at $72.7 \%$ of hospitals. Trauma registries in Hong Kong, Japan, Korea, Malaysia, Singapore, Taiwan, and Uzbekistan contained prehospital information, such as intubation treatment, and some of these registries were even more comprehensive as they were connected to an EMS-based registry. Systematic review programs for trauma care existed in approximately half of the hospitals (53.8\%). Table 4 details the trauma care system of surveyed hospitals. ${ }^{17}$

\section{Trauma outcomes}

Patient data were available for 25 of the 35 EDs. The total number of trauma patients across these sites was 300,376. Eleven $(45.6 \%)$ of these hospitals, located in Japan, Korea, Philippines, Singapore, and Thailand, reported outcomes for ED trauma patients. The overall survival-to-discharge rate in these hospitals was $97.2 \%$, and rates varied from $85.1 \%$ (Taiwan) to $99.7 \%$ (Singapore). The outcomes of trauma patients using EMS were reported in 10 of these hospitals, and these patients tended to have a worse outcome compared to trauma patients in general (survival-to-discharge rate $94.7 \%$ vs. $97.2 \%$, respectively). The average survival-to-discharge rate was $96.3 \%$ in patients with an ISS of 9 to 15 , and $65.1 \%$ in patients with an ISS of $>24$. The difference between survival-to-discharge rate of patients with an ISS of 9 to 15 and patients with an ISS of $>24$ was highest in Taiwan (41.8\%) and lowest in Thailand (18.6\%). Table 5 details trauma outcomes among surveyed hospitals.

\section{DISCUSSION}

We collected and described survey data regarding sociodemographic characteristics, trauma care processes, trauma care structures including education programs and registries, and ED trauma outcomes from 35 individual hospitals across 15 Asia Pacific countries. Our findings showed a wide variety of trauma care systems and outcomes among countries.

Specific trauma care education for medical staff is an essential component of adequate trauma care. ${ }^{14,21,22}$ For example, the Ja- 
Table 2. General hospital information of surveyed hospitals

\begin{tabular}{|c|c|c|c|c|c|c|c|}
\hline & $\begin{array}{c}\text { No. of } \\
\text { surveyed } \\
\text { hospitals }\end{array}$ & $\begin{array}{l}\text { Total no. } \\
\text { of ED visits }\end{array}$ & $\begin{array}{c}\text { Average no. } \\
\text { of ED visits/ } \\
\text { hospital }\end{array}$ & $\begin{array}{l}\text { Urbanization }^{\text {a) }} \\
\text { (no. of hospitals) }\end{array}$ & $\begin{array}{l}\text { Trauma center level } \\
\text { (no. of hospitals) }\end{array}$ & $\begin{array}{c}\text { Hospital level } \\
\text { (no. of hospitals) }\end{array}$ & Census year \\
\hline Total & 35 & $2,276,938$ & 71,154 & $\begin{array}{l}\text { Urban (25), Suburban (4), } \\
\text { Rural (2) }\end{array}$ & $\begin{array}{l}\text { Designated trauma center (9) } \\
\text { General hospital with ED (26) }\end{array}$ & $\begin{array}{l}\text { Tertiary (27), secondary (8), } \\
\text { primary (1) }\end{array}$ & \\
\hline Australia & 1 & 24,272 & 24,272 & Urban (1) & General hospital with ED (1) & Secondary (1) & 2012 \\
\hline China & 1 & 150,000 & 150,000 & Urban (1) & General hospital with ED (1) & Tertiary (1) & 2014 \\
\hline Hong Kong & 1 & 146,000 & 146,000 & Urban (1) & Designated trauma center (1) & Tertiary (1) & 2013 \\
\hline India & 1 & 15,000 & 15,000 & Urban (1) & General hospital with ED (1) & Tertiary (1) & - \\
\hline Indonesia & 1 & - & - & - & General hospital with ED (1) & Secondary (1) & - \\
\hline Japan & 3 & 34,409 & 17,204 & Urban (3) & $\begin{array}{l}\text { Designated trauma center (1) } \\
\text { General hospital with ED (2) }\end{array}$ & Tertiary (3) & 2013 \\
\hline Korea & 12 & 699,905 & 58,325 & $\begin{array}{l}\text { Urban (8), suburban (3), } \\
\text { rural (1) }\end{array}$ & $\begin{array}{l}\text { Designated trauma center (3) } \\
\text { General hospital with ED (9) }\end{array}$ & Tertiary (10), secondary (2) & $\begin{array}{l}2013 \text { (Samsung) } \\
2014 \text { (Others) }\end{array}$ \\
\hline Malaysia & 2 & 209,865 & 104,932 & Urban (1) & General hospital with ED (2) & Tertiary (2) & $\begin{array}{l}2013 \text { (Sungai Buloh) } \\
2014 \text { (HUSM) }\end{array}$ \\
\hline Myanmar & 1 & 18,256 & 18,256 & - & General hospital with ED (1) & Tertiary (1) & 2013 \\
\hline Philippine & 1 & 72,000 & 72,000 & Urban (1) & General hospital with ED (1) & Tertiary (1) & 2014 \\
\hline Singapore & 2 & 309,021 & 154,510 & Urban (2) & $\begin{array}{l}\text { Designated trauma center (1) } \\
\text { General hospital with ED (1) }\end{array}$ & Secondary (2) & 2013 \\
\hline Taiwan & 2 & 235,749 & 117,874 & Urban (2) & Designated trauma center (2) & Tertiary (2) & $\begin{array}{c}2013 \text { (National Taiwan) } \\
2014 \text { (Far Eastern Memorial) }\end{array}$ \\
\hline Thailand & 1 & 50,991 & 50,991 & Rural (1) & Designated trauma center (1) & Tertiary (1) & 2013 \\
\hline Uzbekistan & 1 & 5,000 & 5,000 & Suburban (1) & General hospital with ED (1) & Secondary (1) & - \\
\hline Vietnam & 5 & 306,470 & 76,617 & Urban (4) & General hospital with ED (5) & $\begin{array}{l}\text { Tertiary (3), secondary (1), } \\
\text { primary (1) }\end{array}$ & $\begin{array}{c}2013 \text { (Bach Mai) } \\
2014 \text { (Viet Tiep Friendship) }\end{array}$ \\
\hline
\end{tabular}

ED, emergency department; HUSM, Hospital Universiti Sains Malaysia.

${ }^{a}$ Hospitals which chose more than one option of urban, suburban, and rural were excluded (Sungai Buloh Hospital in Malaysia and Mandalay Hospital in Myanmar).

Table 3. Trauma care process of surveyed hospitals

\begin{tabular}{|c|c|c|c|c|c|c|c|c|c|}
\hline & \multirow[b]{2}{*}{$\begin{array}{l}\text { Highest hospital level for } \\
\text { trauma patient in country }{ }^{17} \\
\text { (no. of hospitals) }\end{array}$} & \multicolumn{3}{|c|}{$\begin{array}{l}\text { Healthcare provider leader level } \\
\text { for trauma (no. of hospitals) }\end{array}$} & \multicolumn{3}{|c|}{ Defined trauma team } & \multirow{2}{*}{$\begin{array}{c}\text { Documented } \\
\text { trauma care } \\
\text { protocol in ED } \\
\text { (no. of hospitals) }\end{array}$} & \multirow{2}{*}{$\begin{array}{l}\text { Certification/ } \\
\text { license for } \\
\text { trauma surgeons } \\
\text { (no. of hospitals) }\end{array}$} \\
\hline & & $\begin{array}{l}\text { No. of } \\
\text { trauma } \\
\text { surgeons }\end{array}$ & $\begin{array}{c}\text { No. of } \\
\text { emergency } \\
\text { physicians }\end{array}$ & $\begin{array}{l}\text { No. of } \\
\text { general or } \\
\text { department } \\
\text { surgeons }\end{array}$ & $\begin{array}{c}\text { No. of } \\
\text { hospitals with } \\
\text { trauma team }\end{array}$ & $\begin{array}{l}\text { Average no. } \\
\text { of persons in a } \\
\text { trauma team }\end{array}$ & $\begin{array}{c}\text { Protocol for } \\
\text { trauma team } \\
\text { (no. of hospitals) }\end{array}$ & & \\
\hline Total & $\begin{array}{l}\text { Designated trauma center (23) } \\
\text { General hospital with ED (10) }\end{array}$ & 18 & 28 & 12 & 18 & 6 & $16(88.9 \%)$ & $25(75.8 \%)$ & $22(66.7 \%)$ \\
\hline Australia & Designated trauma center (1) & 0 & 1 & 0 & 0 & - & - & 1 & 0 \\
\hline China & Designated trauma center (1) & 1 & 0 & 1 & 1 & 5 & 1 & 1 & 1 \\
\hline Hong Kong & Designated trauma center (1) & 0 & 1 & 0 & 1 & 5 & 1 & 1 & 0 \\
\hline India & Designated trauma center (1) & 1 & 1 & 1 & 0 & - & - & 0 & 0 \\
\hline Indonesia & General hospital with ED (1) & 1 & 0 & 1 & 0 & - & - & 1 & 1 \\
\hline Japan & $\begin{array}{l}\text { Designated trauma center (2) } \\
\text { General hospital with ED (1) }\end{array}$ & 1 & 3 & 0 & 0 & - & - & $2(66.7 \%)$ & $2(66.7 \%)$ \\
\hline Korea & Designated trauma center (11) & 5 & 11 & 4 & 5 & 6.6 & 5 & $8(72.7 \%)$ & $10(90.9 \%)$ \\
\hline Malaysia & General hospital with ED (2) & 0 & 2 & 0 & 1 & 7 & 1 & $1(50 \%)$ & $1(50 \%)$ \\
\hline Myanmar & - & 1 & 1 & 1 & 1 & - & 1 & 1 & 1 \\
\hline Philippine & Designated trauma center (1) & 0 & 1 & 0 & 1 & 4 & 1 & 1 & 1 \\
\hline Singapore & $\begin{array}{l}\text { Designated trauma center (1) } \\
\text { General hospital with ED (1) }\end{array}$ & 2 & 1 & 1 & 2 & 8 & 2 & 1 & 0 \\
\hline Taiwan & Designated trauma center (2) & 2 & 2 & 0 & 2 & 9.5 & 2 & $1(50 \%)$ & $1(50 \%)$ \\
\hline Thailand & Designated trauma center (1) & 1 & 0 & 0 & 1 & 3 & 1 & 1 & 1 \\
\hline Uzbekistan & General hospital with ED (1) & 1 & 1 & 1 & 0 & - & - & 0 & 0 \\
\hline Vietnam & $\begin{array}{l}\text { Designated trauma center (1) } \\
\text { General hospital with ED (4) }\end{array}$ & 2 & 3 & 2 & 3 & 3 & 2 & $4(80 \%)$ & $3(60 \%)$ \\
\hline
\end{tabular}

$E D$, emergency department. 
Table 4. Trauma care structure of surveyed hospitals

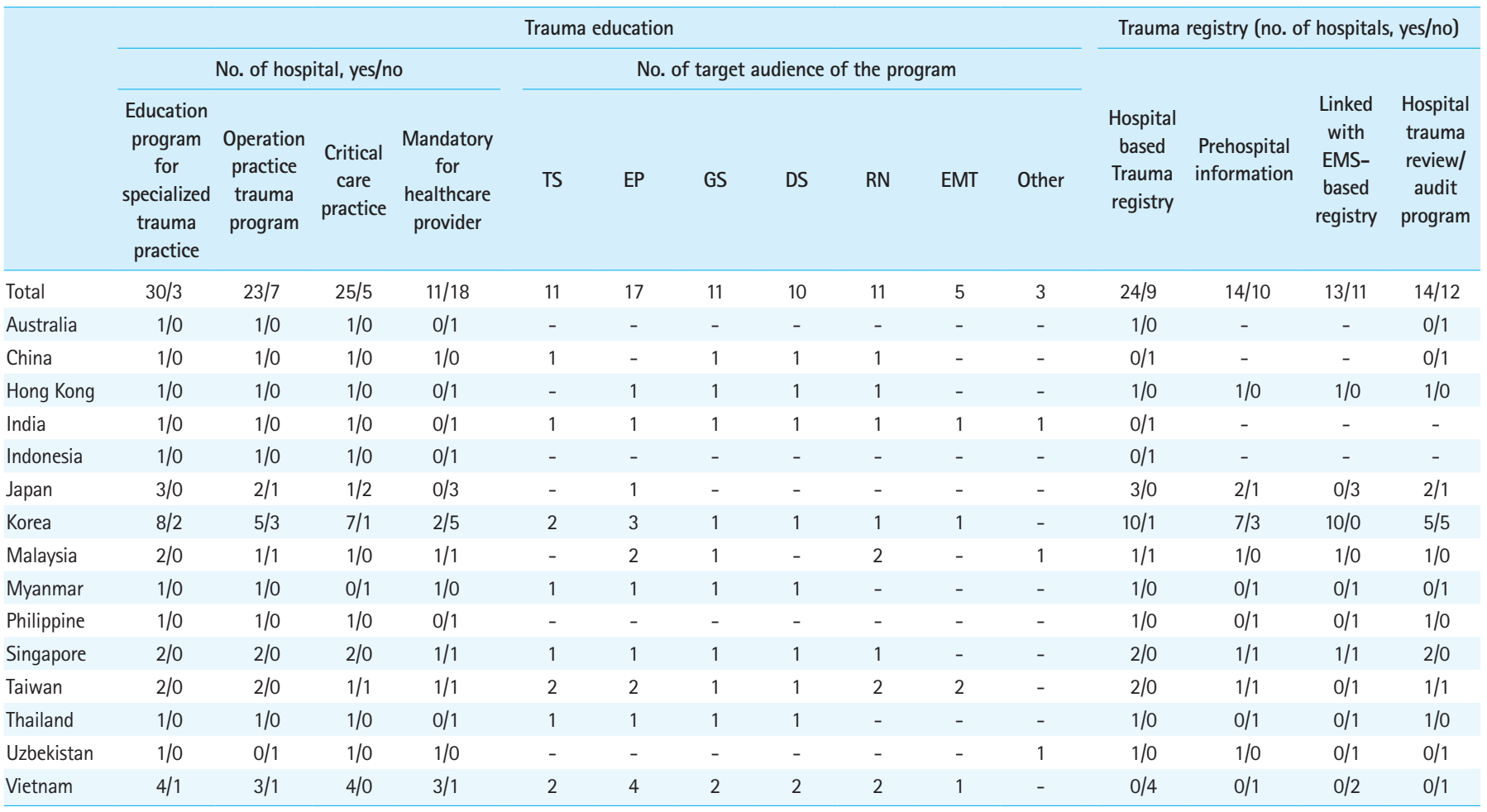

TS, trauma surgeon; EP, emergency physician; GS, general surgeon; DS, department surgeon; RN, registered nurse; EMT, emergency medical technician; EMS, emergency medical service.

Table 5. Trauma ED outcomes of surveyed hospitals

\begin{tabular}{|c|c|c|c|c|c|c|c|c|c|c|}
\hline & \multicolumn{2}{|c|}{ Trauma patients in ED } & \multicolumn{2}{|c|}{ Trauma patients via EMS in ED } & \multicolumn{6}{|c|}{ Trauma severity } \\
\hline & \multirow{3}{*}{$\begin{array}{c}\text { Total visits } \\
(n=25)\end{array}$} & \multirow{3}{*}{ 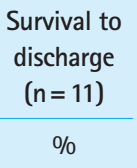 } & \multirow{3}{*}{$\begin{array}{c}\text { Total visits } \\
(n=17) \\
\text { No. }\end{array}$} & \multirow{3}{*}{$\begin{array}{c}\begin{array}{c}\text { Survival to } \\
\text { discharge } \\
(\mathrm{n}=10)\end{array} \\
\%\end{array}$} & \multirow{2}{*}{\multicolumn{2}{|c|}{$\begin{array}{c}\text { ISS 9-15 } \\
\text { Survival discharge }\end{array}$}} & \multirow{2}{*}{\multicolumn{2}{|c|}{$\begin{array}{c}\text { ISS 16-24 } \\
\text { Survival discharge }\end{array}$}} & \multirow{2}{*}{\multicolumn{2}{|c|}{$\begin{array}{c}\text { ISS }>24 \\
\text { Survival discharge }\end{array}$}} \\
\hline & & & & & & & & & & \\
\hline & & & & & No. & $\%$ & No. & $\%$ & No. & $\%$ \\
\hline Total & 300,376 & 97.2 & 32,556 & 94.7 & 4,369 & 96.3 & 1,540 & 91.3 & 1,090 & 65.1 \\
\hline Australia & - & - & - & - & - & - & - & - & - & - \\
\hline Hong Kong & 600 & - & - & - & - & - & - & - & - & - \\
\hline India & - & - & - & - & - & - & - & - & - & - \\
\hline Indonesia & - & - & - & - & - & - & - & - & - & - \\
\hline Japan & 2,656 & 99.3 & 3,870 & 97.8 & 402 & 98.0 & 269 & 94.4 & 229 & 68.1 \\
\hline Korea & 147,928 & 98.8 & 20,273 & 97.2 & 2,400 & 94.5 & 806 & 88.2 & 439 & 63.6 \\
\hline Taiwan & 14,370 & 85.1 & 2,307 & 72.2 & 674 & 99.6 & 180 & 96.7 & 116 & 57.8 \\
\hline Thailand & 10,049 & 99.3 & 925 & 98.6 & 366 & 95.9 & 142 & 90.8 & 141 & 77.3 \\
\hline Uzbekistan & 2,000 & - & - & - & - & - & - & - & - & - \\
\hline Vietnam & 38,390 & - & - & - & - & - & - & - & - & - \\
\hline
\end{tabular}

ED, emergency department; EMS, emergency medical service; ISS, injury severity score.

pan Advanced Trauma Evaluation and Care education program significantly reduced trauma mortality. ${ }^{22}$ Most hospitals in our study had established trauma-specialized education programs, but $60 \%$ of them were not mandatory, and education programs 
for paramedics were insufficient. The shortage of standardized and organized educational programs for trauma care in Asian countries has also been reported by other studies. ${ }^{14,21,22}$

Injury surveillance guidelines, ${ }_{1}^{23}$ published by the WHO in 2001, strongly recommended injury surveillance systems with qualified, extensive injury data. The American College of Surgeons also emphasizes the importance of trauma registries for evaluating trauma systems. ${ }^{24}$ We expect the PATOS to function in a similar way to the National Trauma Data Bank of the United States, ${ }_{1}^{25}$ National Trauma Registry of Canada ${ }_{1}^{26}$ Trauma Registry of the German Society for Trauma Surgery, ${ }_{1}^{27}$ and EuroTARN-the Collaborative European Registry of Trauma of 14 European countries, ${ }_{1}^{28}$ by serving as a platform for analyzing trauma indices, comparing trauma care systems, and examining various risk factors and predictors of trauma in this region. We found that some hospitals in Hong Kong, Malaysia, Singapore, and Korea had linked registries for prehospital and hospital data, but others lacked this resource. PATOS will provide a reference to compare the benefits of resources like these to trauma outcomes across the Asia Pacific.

In our study, 75\% of participating hospitals offered tertiary care, but only $25 \%$ had designated trauma centers. In Indonesia, Malaysia, and Uzbekistan, the highest hospital level for trauma patients was a general hospital, not designated as a trauma center; however, some hospitals in these countries were equipped with trauma teams. Designated trauma centers have been shown to improve survival and cost-effectiveness in several studies. ${ }^{11,29}$ The United States has more than 1,000 trauma centers and manages the quality of services through American College of Surgeons certification. ${ }^{30}$ India has established the Jai Prakash Narayan Apex Trauma Center at the All India Institute of Medical Sciences in New Delhi, ${ }^{10}$ and in South Korea, regional trauma centers have been designated and are currently being built. ${ }^{31}$ In Australia, the introduction of a statewide trauma system was associated with significant improvements in trauma care outcomes. ${ }^{32}$

It was not possible to collect ED trauma outcome data from some of the countries in this study. This may be attributed to the lack of trauma registries. One previous study reported that the mortality rate of injuries (ISS $\geq 9$ ) rose from $35 \%$ in high-income settings to $63 \%$ in low-income settings, ${ }^{33}$ and a similar study showed that moderate injuries were associated with a $6 \%$ mortality rate in high-income countries, and a much higher 36\% mortality rate in low-income countries. ${ }^{34}$ In the current study, it is notable that survival-to-discharge rates for total trauma patients and trauma patients transferred using the EMS in Taiwan were both lower (85.1\% and $72.2 \%$, respectively) compared to other developed countries, and survival-to-discharge rates from moderate-to-severe trauma in South Korea did not meet the av- erage. A previous study found trauma care outcomes in Japan to be unfavorable; the preventable death rate in Japan was $11 \% 0^{13}$ compared to between $1 \%$ and $7 \%$ in the United States. ${ }^{35,36}$

One limitation of this study was the small number of respondents for trauma outcomes (total ED survival $[n=11]$ and survival rate by ISS $[n=9]$ ), which reduces the impact of comparisons between components of trauma care and mortality. Another limitation was lack of representation; our study generally included one to three hospitals per country, apart from the 11 hospitals in South Korea and the five hospitals in Vietnam. This potential selection bias makes it difficult to generalize our results, leaving us with only a partial understanding of the overall state of trauma care systems in each country. Moreover, we need to be careful when interpreting the results of this study because of profound discrepancies in the definitions of variables, and data quality. For example, standards for a designated trauma center could be different between countries, and the curriculum of education programs for trauma care could be more or less comprehensive in different countries. Some countries provided estimates rather than predefined and measured data, and exact data was often not available because trauma registries were not yet organized sufficiently. Missing or roughly estimated data for several variables, particularly trauma treatment outcomes, limited a robust description and comparison.

Our findings emphasize the differences in trauma ED outcomes across Asian trauma care settings, and support the need for a detailed, customized, and systematic trauma surveillance platform like PATOS. This study provides evidence-based data for the construction of organized trauma care systems based on a comprehensive trauma database, thereby helping to improve trauma outcomes in this region.

\section{CONFLICT OF INTEREST}

No potential conflict of interest relevant to this article was reported.

\section{ACKNOWLEDGMENTS}

This paper was supported by Wonkwang University in 2018.

\section{REFERENCES}

1. World Health Organization. Injuries and violence: the facts. Geneva: World Health Organization; 2010.

2. World Health Organization. Global health estimates 2014 summary tables: DALY by cause, age and sex, 2000-2012. Ge- 
neva: World Health Organization; 2014.

3. Organization for Economic Co-operation and Development; World Health Organization. Health at a glance: Asia/Pacific 2012. Paris: OECD Publishing; 2012.

4. Calland JF, Xin W, Stukenborg GJ. Effects of leading mortality risk factors among trauma patients vary by age. J Trauma Acute Care Surg 2013;75:501-5.

5. Mann NC, Mullins RJ, MacKenzie EJ, Jurkovich GJ, Mock CN. Systematic review of published evidence regarding trauma system effectiveness. J Trauma 1999;47:S25-33.

6. Sampalis JS, Denis R, Lavoie A, et al. Trauma care regionalization: a process-outcome evaluation. J Trauma 1999;46:565-79.

7. Rhodes $M$, Aronson J, Moerkirk G, Petrash E. Quality of life after the trauma center. J Trauma 1988;28:931-8.

8. MacKenzie EJ, Siegel JH, Shapiro S, Moody M, Smith RT. Functional recovery and medical costs of trauma: an analysis by type and severity of injury. J Trauma 1988;28:281-97.

9. Bazzoli GJ, Madura KJ, Cooper GF, MacKenzie EJ, Maier RV. Progress in the development of trauma systems in the United States. Results of a national survey. JAMA 1995;273:395-401.

10. Prada SI, Salkever D, MacKenzie EJ. Level-I trauma centre treatment effects on return to work in teaching hospitals. Injury 2014;45:1465-9.

11. Mullins RJ, Veum-Stone J, Helfand M, et al. Outcome of hospitalized injured patients after institution of a trauma system in an urban area. JAMA 1994;271:1919-24.

12. Nguyen $T L$, Nguyen $T H$, Morita $S$, Sakamoto J. Injury and prehospital trauma care in Hanoi, Vietnam. Injury 2008;39:102633.

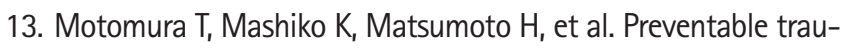
ma deaths after traffic accidents in Chiba Prefecture, Japan, 2011: problems and solutions. J Nippon Med Sch 2014;81:3207.

14. Joshipura MK. Trauma care in India: current scenario. World J Surg 2008;32:1613-7.

15. Jiang BG. Status of road traffic injury rescue and current work in China. Chin Med J (Engl) 2011;124:3850-1.

16. Yin $X F$, Wang TB, Zhang PX, et al. Evaluation of the effects of standard rescue procedure on severe trauma treatment in china. Chin Med J (Engl) 2015;128:1301-5.

17. Central Intelligence Agency. The world factbook [Internet]. Washington, DC: Central Intelligence Agency [cited 2018 Oct 9]. Available from: https://www.cia.gov/library/publications/ resources/the-world-factbook/fields/335rank.html.

18. World Health Organization. World health statistics 2015. Geneva: World Health Organization; 2015.

19. United Nations. World population prospects: 2015 revision
[Internet]. New York, NY: United Nations; 2015 [cited 2018 Oct 9]. Available from: https://www.un.org/en/development/ desa/publications/world-population-prospects-2015-revision. html.

20. National Statistics. National statistics of Taiwan [Internet]. [place unknown]: National Statistics; 2014 [cited 2018 0ct 9]. Available from: http://statdb.dgbas.gov.tw/.

21. MacKenzie EJ, Rivara FP, Jurkovich GJ, et al. A national evaluation of the effect of trauma-center care on mortality. N Engl J Med 2006;354:366-78.

22. MacKenzie E, Hoyt DB, Sacra JC, et al. National inventory of hospital trauma centers. JAMA 2003;289:1515-22.

23. Byun CS, Park IH, Oh JH, Bae KS, Lee KH, Lee E. Epidemiology of trauma patients and analysis of 268 mortality cases: trends of a single center in Korea. Yonsei Med J 2015;56:220-6.

24. Zong ZW, Li N, Cheng TM, et al. Current state and future perspectives of trauma care system in mainland China. Injury 2011;42:874-8.

25. Hondo K, Shiraishi A, Fujie S, Saitoh D, Otomo Y. In-hospital trauma mortality has decreased in Japan possibly due to trauma education. J Am Coll Surg 2013;217:850-7.

26. Holder Y, Peden M, Krug E, Lund J, Gururaj G, Kobusingye 0. Injury surveillance guidelines. Geneva: World Health Organization; 2001.

27. American College of Surgeons, Committee on Trauma. Resources for optimal care of the injured patient 2014. Chicago, IL: American College of Surgeons; 2014.

28. National Trauma Data Bank. Welcome to the NTDB Data Center [Internet]. Chicago, IL: American College of Surgeons [cited 2018 Oct 9]. Available from: https://www.ntdbdatacenter. com/Default.aspx.

29. National Trauma Registry. Trauma and injuries [Internet]. Ottawa, ON: Canadian Institute for Health Information [cited 2018 Oct 9]. Available from: https://www.cihi.ca/en/types-ofcare/specialized-services/trauma-and-injuries.

30. Ruchholtz S. The trauma registry of the german society of trauma surgery as a basis for interclinical quality management. a multicenter study of the German society of trauma surgery. Unfallchirurg 2000;103:30-7.

31. EuroTARN. The Trauma Audit \&t Research Network: introduction [Internet]. Salford: TARN [cited 2018 Oct 9]. Available from: https://www.tarn.ac.uk/Content.aspx?ca $=8$.

32. Mock CN, Jurkovich GJ, nii-Amon-Kotei $D$, Arreola-Risa $C$, Maier RV. Trauma mortality patterns in three nations at different economic levels: implications for global trauma system development. J Trauma 1998;44:804-12.

33. Mock CN, Adzotor KE, Conklin E, Denno DM, Jurkovich GJ. 
Trauma outcomes in the rural developing world: comparison with an urban level I trauma center. J Trauma 1993;35:518-23.

34. Sanddal TL, Esposito TJ, Whitney JR, et al. Analysis of preventable trauma deaths and opportunities for trauma care improvement in utah. J Trauma 2011;70:970-7.

35. Teixeira PG, Inaba K, Hadjizacharia P, et al. Preventable or po- tentially preventable mortality at a mature trauma center. J Trauma 2007;63:1338-46.

36. Cameron PA, Gabbe BJ, Cooper DJ, Walker T, Judson R, McNeil J. A statewide system of trauma care in Victoria: effect on patient survival. Med J Aust 2008;189:546-50. 